\title{
Malay Version of Moral Identity Scale: A Cross-Cultural Validation in Malaysian Youth
}

\author{
Yusoff $\mathbf{N}^{\mathrm{a}}$, Shaharum $\mathbf{M H}^{\mathbf{b}}$, Kueh $\mathbf{Y C}^{\mathrm{c}}$ \\ ${ }^{a}$ Department of Neurosciences, School of Medical Sciences, Health Campus Universiti Sains Malaysia, Kelantan, Malaysia \\ ${ }^{b}$ Department of Neurosciences, School of Medical Sciences, Health Campus Universiti Sains Malaysia, Kelantan, Malaysia . \\ 'Unit of Biostatistics and Research Methodology, School of Medical Sciences, Health Campus, Universiti Sains Malaysia
}

Keywords

Moral Identity Scale, cross-cultural

validation, internalisation, symbolisation,

reliability, confirmatory factor analysis.

Corresponding Author

Dr. Nasir Yusoff

Department of Neurosciences, School of

Medical Sciences, Health Campus

Universiti Sains Malaysia, 16150 Kubang

Kerian, Kelantan, Malaysia

Tel No : 609-7676300/0179788554

Email: nasirff@usm.my

Received: 11th August 2021; Accepted: 28th October 2021

Doi: https://doi.org/10.31436/imjm.v21i1

\section{ABSTRACT}

INTRODUCTION: The Moral Identity Scale (MIS) measures the construct of moral identity-internalisation and symbolisation. This study aims to translate and validate the original English version of MIS to the Malay language version. MATERIALS AND METHODS: A total of 388 participants from Kota Bharu, Kelantan, were recruited through convenient sampling for the cross-sectional online survey, which ran from December 2020 to February 2021. Participants were chosen who were between the ages of 18 and 24, had internet access, and could read and communicate in the Malay language. The MIS, which was translated into Malay using forward and backward procedures, was distributed alongside the socio-demographic form. Confirmatory factor analysis (CFA), discriminant validity, construct reliability, and the test-retest Intraclass Correlation Coefficient (ICC) were performed using Mplus 8.3.

RESULTS: Participants' mean age was 22 years old. More than half were females. The construct of moral identity was maintained with the re-modeling of internalisation. The final model suggested retaining the three internalisation items and five symbolisation items. Discriminant validity and the construct reliability of the two factors were satisfactory (symbolisation $=0.81$, internalisation $=0.69$ ). Internal consistencies indicated acceptable Cronbach's alpha values for both symbolisation (0.85) and internalisation (0.81). Test-retest Intraclass Correlation Coefficient (ICC) was good and satisfactory (internalisation $=0.79$ and symbolisation $=0.81$ ). CONCLUSION: The Malay version of MIS is a reliable tool and free from cultural bias which is useful to be applied in a public health-related program.

\section{INTRODUCTION}

Moral identity is described as one kind of self-regulatory mechanism that constructs one's self-concept and motivates moral action. ${ }^{1,2}$ It is believed that some people consider morality as central to their identities, whereas others consider more pragmatic traits as central to their self-concepts. From this thought, the approach to understanding moral traits (through the paradigm of moral identity) has been conceptualised by Aquino and Reed. ${ }^{1}$ In this conceptualisation of moral identity, two dimensions of moral dimension are proposedinternalisation and symbolisation. Internalisation is the degree to which moral principles are central to one's selfconcept and it concerns the private or personal aspect of self. Symbolisation reflects the extent to which moral principles are expressed externally to others and the concerns of the public or social aspect of the moral self. ${ }^{1}$ The model of morality such as from Blasi Self Model stressed that morality is not simply about what is right or wrong - it is about 'self-defining'. ${ }^{3}$ This model has long been standing to the fact that moral identity is being constructed from the extent to which being moral is central or essential to one's sense of self. Different from other moral paradigms (such as moral competency and moral reasoning), moral identity, indeed, was introduced as a basic construct of self (self-conception), which is associated with certain beliefs, attitudes, and behaviors. ${ }^{4}$ It is also said that moral identity is a parameter of social identity, which is constructed and grounded from theories 
surrounding self-concept and social identity. ${ }^{5}$ In earlier documentation, the important concept of 'identity' has been once stressed by a moral psychologist who said that identity is rooted in the very core of one's being, involves being true to oneself in action, and is associated with respect for one's understanding of reality. ${ }^{6}$ The later model of self-identity further suggested that identity includes some elements of the ideal self and functions as the ideal principle of action. ${ }^{7}$

Youth's moral issue indicates a significant link to various psychosocial outcomes. The significant interplay between youth's conflict of morals and their tendency towards risky behaviour, ${ }^{8}$ conveys the message that the mature sense of moral identity may lead to better mental health and less risk-taking behaviours. ${ }^{9}$

The Moral Identity Scale (MIS) is a well-known scale among moral-psychologist who intent to capture the implicit and explicit value of moral identity that interprets the thinking pattern and action of the young adult group of population. ${ }^{1}$ The moral issue of adolescents and youth is crucial because this life phase is a transition period from childhood to adulthood, accompanied by dramatic biological and psychological transformations in response to change in the hormone, thinking process, and social life. This life cycle is known as a very challenging life period depicted by a high involvement in risk-taking behavior. ${ }^{10}$ Thus, research surrounding the moral issues among Malaysian youth demands the cross-cultural adaption to be implemented for MIS in order to produce a validated screening tool that is free from cultural bias and language barriers.

\section{MATERIALS \& METHODS}

\section{Study Design and Participants}

In this cross-sectional validation study that was implemented between December 2020 to February 2021, the general population aged 18 to 24 years old from Kota Bharu, Kelantan were invited to take part through the advertisement circulated on social media. Before enrollment, participants were screened for eligibility. Those who had psychological abnormalities and were illiterate were not selected as a participant. Only those who were within the youth age range (18-24 years old), had internet access, and were able to read and communicate in the Malay language were selected as participants.

\section{Sampling Method and Data Collection Procedure}

Data collection began after the study protocol was approved by the Human Ethics Committee of USM (JEPeM USM Code: USM/JEPeM/19120927). By using the convenience sampling method, a total of 388 participants took part in the study and completed an online google survey form which consisted of sociodemographic information and the Moral Identity ScaleMalay Version (MIS-M). Before the online data collection was initiated, a detailed explanation of the study procedure and objectives (i.e. Research Information Sheet) was delivered to the participants through their e-mail. They were allowed to ask any related questions to the researcher by using any communication methods such as phone and e-mail. Participants were informed that the study was entirely voluntary and can withdraw at any time. Participants who agreed to participate were required to submit a copy of the signed consent form to the researcher through e-mail. Participants took approximately 5-10 minutes to complete the online google survey form. All the complete data was then automatically directed to the researcher's google drive with a specific ID for compilation and data entry.

In addition, a test-retest measure (after a two-week interval) was implemented among 30 participants to determine the stability of the MIS-M. They were randomly selected from the 388 participants in the initial data collection. Before obtaining participants' consent for this re-test phase, they were briefed on the purpose of the retest or second measure of the study. Then, the participants completed the MIS-M again through the online google survey form.

\section{Moral Identity Scale}

\section{Tool description and translation}

The original English version of the Moral Identity Scale is a scale that measures two domains-internalisation and 
symbolisation. Internalisation captures the intrinsic value that is important in one's self-concept measured through five items. For example, "it would make me feel good to be a person who has these characteristics". Meanwhile, symbolisation is a domain that measures one's external value that interprets the internalisation from five items. For example, "I often wear clothes that identify me as having these characteristics". This scale uses seven Likert options (the lowest score of one for 'completely disagree' to the highest score of seven for 'completely agree') in response to the above-mentioned items whilst participants visualised the following nine positive characteristics in their mind that might illustrate a person self-identity - caring, compassionate, fair, friendly, generous, helpful, hardworking, honest and kind. The construct validity of the scale has been established and reported. 1

The original 10 items of the Moral Identity Scale and its instruction were translated into the Malay language (also known as Malaysia language) which is the national language in Malaysia. Brislin's forward and backward method was used in translation procedure to assure the equivalent meaning and psychometric property between the two different language ${ }^{11}$ - English and Malay language. In this procedure, four translators (Malay and English bilinguist) were hired-two translators were asked to translate the original English into Malay language (Forward step). Meanwhile, the other two were asked to translate the new Malay version (pre-final 1) into a new English version. The final Malay version was produced after the agreement between the two translators at backward step was achieved with regards to the ambiguity and unclarity of the words and sentences (between the original English and the new English version). The procedure was repeated if necessary. The final version was then pre-tested in 10 respondents.

\section{Data Entry and Internal Structure}

Data analysis was conducted using Mplus 8.3. Categorical variables were described using frequency and percentage whereas numerical variables were presented by the mean and standard deviation (SD). Confirmatory factor analysis (CFA) was conducted to examine the validity of the MIS-M. The initial hypothesised MIS-M model consisted of 10 items and two latent variables (symbolisation and internalisation). The data were checked for multivariate normality and results indicated that the data did not meet the assumption with a significant $p$-value of Mardia multivariate skew $(\mathrm{p}<0.001)$ and kurtosis $(\mathrm{p}<0.001)$. Therefore, a robust maximum likelihood estimator (MLR) was used in the CFA analysis. Several fit indices were used to assess the fitness of the model to the data. The Comparative Fit Index (CFI) and Turker and Lewis Index (TLI) with a value above 0.90 usually associated with the model that fits well, the root mean square error of approximation (RMSEA) and the standardised root mean square (SRMR) with the desired value of below 0.08 which indicate the model fits well. ${ }^{12,13}$ Items with factor loading less than 0.50 were considered problematic items. ${ }^{13}$ The items were subjected to removal from the model after adequate theoretical support was carried out. Besides the factor loading, the CFA modification index (MI) was inspected during model re-specification to obtain a fit measurement model. Based on the highest value of MI, the correlation between items' residuals would be added within the same factor and the model fitness was inspected again. After the best fit model was obtained, the correlation between the two latent variables was inspected. Correlation with a value less than 0.85 indicates discriminant validity was achieved .14 Reliability of the final measurement model was assessed using construct reliability based on Raykov's method in Mplus 8.3.15 The minimum acceptable range of construct reliability is 0.60 and above. ${ }^{13}$ The internal consistency reliability based on Cronbach's alpha was also reported. The minimum acceptable range of the reliability value is 0.60 and above. ${ }^{13}$

Test-retest reliability analysis was also performed to determine the consistency of reliability of each sub-scale following one month indicated by the intraclass correlation coefficient (ICC) as follows: poor for the ICC $<.40$, fair to good for the ICC between .40 and .75, and good for the ICC $>.75$ (Fleiss, 1986). ${ }^{16}$

\section{Sample Size Determination}

According to Hair et al. ${ }^{13}$, the minimum sample size for models with fewer factors and lower communalities was 
about 300. However, In CFA, a larger sample size generally produces more stable results and is more likely to be replicable. ${ }^{13}$ Therefore, the sample for the present study of 388 participants is considered adequate.

\section{RESULTS}

Data were screened and cleaned from any wrong entries and missing values. A total final sample of 388 was used in the analysis. The mean age of participants was $22 \pm 1.7$ years old, ranging from 18-24 years old. More than half of the participants were female $(\mathrm{N}=62 \%)$. In terms of ethnicity, a large proportion was from Malays (79\%) followed by Chinese (12\%) and Indian (5\%). A small percentage was from another minority ethnic (4\%).

In the initial testing hypothesised MIS-M measurement model, the standardised item loadings ranged from 0.15 to 0.86 (Figure 1). Based on the output, the fit indices of the initial model were not within the acceptable values (Table 1, Model 1). Two items with factor loading below 0.40

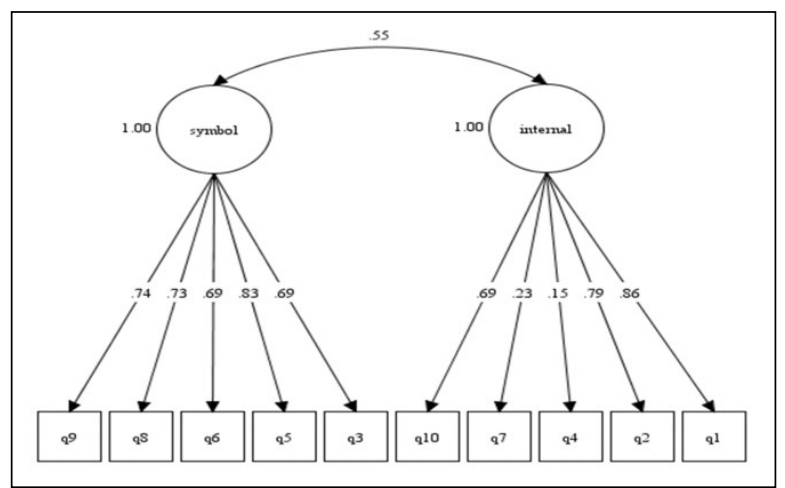

Note: symbol $=$ Symbolisation, internal $=$ Internalisation, $\mathrm{q} 1$ to $\mathrm{q} 10$ are the items of MIS-M.

Figure 1. Initial measurement model of MIS-M

Table I: Goodness of Fit Indices for Measurement Model of MIS-M (Initial to Final Models)

\begin{tabular}{lllll}
\hline Model & CFI & TLI & SRMR & $\begin{array}{l}\text { RMSEA } \\
(90 \% \mathrm{CI})\end{array}$ \\
\hline $\begin{array}{l}\text { Model 1 } \\
\text { Initial Model) }\end{array}$ & 0.751 & 0.670 & 0.117 & $\begin{array}{l}0.149 \\
(0.135,0.164)\end{array}$ \\
Model 2 & 0.893 & 0.843 & 0.058 & $\begin{array}{l}0.115 \\
(0.095,0.135)\end{array}$ \\
$\begin{array}{l}\text { Model 3 (Final } \\
\text { Model) }\end{array}$ & 0.952 & 0.921 & 0.055 & 0.080 \\
\hline
\end{tabular}

Notes. CFI $=$ Comparative Fit Index, TLI $=$ Tucker-Lewis Index, SRMR = Standardised Root Mean Square Residual, RMSEA = Root Mean Square Error of Approximation, $\mathrm{CI}=$ Confidence Interval

a Model with added correlated items' residual (q8 with q9, q2 with q10) were identified. The model was re-specified by removing the two items iteratively (i.e. item numbers 4 and 7). The fit indices of the re-specified model (Table 1, Model 2) have improved but still not achieved the acceptable fit value.

A further investigation was carried out on Model 2. Two correlations between items' residuals with high MI values

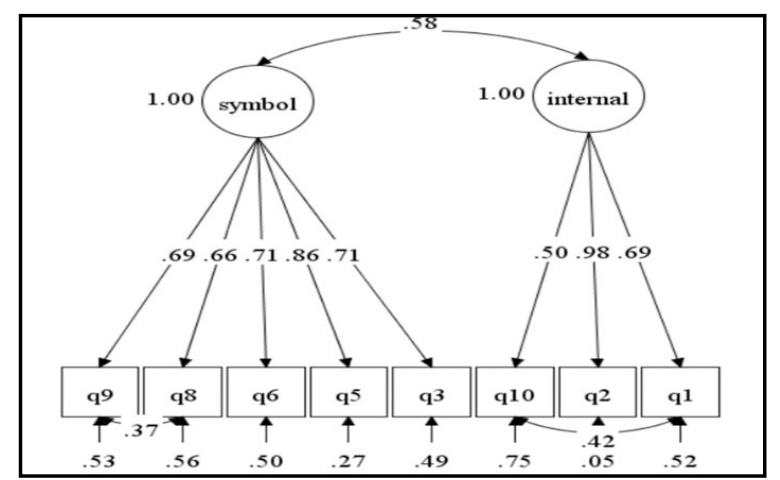

Note: symbol $=$ Symbolisation, internal $=$ Internalisation, $\mathrm{q} 1$ to $\mathrm{q} 10$ are the items of MIS-M.

Figure 2: Final measurement model of MIS-M.

were added into the model iteratively after adequate theoretical support was carried out by the researchers. This resulted in a good fit model based on the several fit indices (Table 1, Model 3). Figure 2 illustrates the final measurement model of MIS-M. The factor loadings ranged from 0.67 to 0.98 .

The correlation between the two factors was 0.54 which is below the value of 0.85 . This indicated that the discriminant validity of the MIS-M was satisfactory. The construct reliability was computed based on the final model of MIS-M. The construct reliability of symbolisation and internalisation were 0.81 and 0.69 respectively. This indicated the reliability of the two factors model of MIS-M was satisfactory. In addition, the reliability based on Cronbach's alpha value for symbolisation and internalisation were 0.85 and 0.81 respectively which indicated acceptable internal consistency reliability for MIS-M.

Test-retest (after two weeks interval) was carried out among 30 participants randomly selected from the 388 participants in the initial data collection. The value of the Intraclass Correlation Coefficient (ICC) was good-0.79 for internalisation and 0.81 for symbolisation. 


\section{DISCUSSION}

The eight items of the Malay Version of Moral Identity Scale (i.e. three items of internalisation and five items of symbolisation) indicate acceptable psychometric properties for the use of Malay language speakers. The original English version of the Moral Identity Scale was translated into Malay language version (through forwards and backward technique) to cater to the cross-cultural issue that may arise in order to avoid any cultural-related bias such as misinterpretation of meaning in a different language. ${ }^{17}$ Malay language is an official spoken language of Malay people and is usually used by other Malaysians too like Chinese, Indian, and other Malaysian minorities. The Malay language is declared as the first language in Malaysia due to the large percentage of the Malay population (almost $50 \%$ of the entire population) in Malaysia. ${ }^{18}$ In the meantime, English is adopted as the second language of the country. The historical background of British colonization in Malaysia (formerly known as Tanah Melayu) many decades ago is a rationale of recognising English as a second language in Malaysia by the government. The Malay language is spoken by approximately 290 million people in Malaysia and many regions in South East Asia such as Indonesia, Brunei, and Singapore, as well as some small regions in East Timor and Thailand. It is reported that the Malay language spread and rapidly grew during the reign of the Malaccan Sultanate around the $15^{\text {th }}$ century. ${ }^{19}$ The structure of the Malay language is much different from the English language that needs very careful translation. ${ }^{20}$ The construct validity of two domains i.e. internalization and symbolization has been proven by this Malay version of the Moral Identity scale. This translated version maintains the internalisation and symbolisation as a construct of moral identity which suggests moral identity as a positive trend between the internal value (internalisation) and external value (symbolisation). In this construct, internalisation is understood as an intrinsic positive value (i.e. caring, compassionate, fair, friendly, generous, helpful, hardworking, honest, kind) that strengthens one's self-concept. Meanwhile, symbolisation is vice versa - an external value that is interpreted through action as guided by that intrinsic value. ${ }^{1}$ The construct of moral identity-internalisation and symbolisation are dual psycho-moral factors that have been proven to positively correlate with various parameters of prosocial activities. ${ }^{21,22}$ This translated version of the Moral Identity Scale indicates an ability to capture moral identity as a selfregulatory mechanism or schemas that guide moral action, which is in line with the expectation from the previous established moral cognition model like Blasi Model.3,7

However, it is not unusual to find the different patterns of moral identity construct in these two domainssymbolisation and internalisation. The nonconformity of these two psycho-moral elements is possible. For example, researchers found that symbolisation is a dominant trait than internalisation that significantly predicted most prosocial domains. ${ }^{23}$ Meanwhile, another study reported that, even though internalisation and symbolisation are equivalently vital for proscriptive moral outcomes, internalisation is indicated as a more significant domain than symbolisation to control the prescriptive moral outcomes. ${ }^{24}$

There are also other moral identity scales with different domain focus around the globe that has been translated into different languages. For example, the Moral Identity Questionnaire (MIQ) that measures two different domains of moral identity (i.e. moral integrity and moral self), was translated into the Spanish language. 25 Different from Moral Identity Scale as developed by Aquino and Reed $^{1}$, this MIQ proposes the moral integrity domain as one of the underlying concepts of morality. The term integrity is defined as the quality of acting in accordance or harmony with relevant moral values, norms, and rules, a choice based partly on some of the arguments that have already been put forward. ${ }^{26}$ Huberts also mentioned that an integrity judgment always raises the moral dimension, the question of what is considered right and wrong. Integrity towards moral identity is a focused aspect of internalisation meanwhile the aspect of internalisation is the general and broader aspect of internal factors and internal reasoning. This translated version of MIQ indicated excellence domain coherence and language clearness. ${ }^{25}$ Meanwhile, in another scale such as the Moral Identity Test, the construct of moral identity is proposed as a single construct that can be measured with ten items. $^{27}$ 


\section{CONCLUSION}

The Malay Version of Moral Identity Scale (MIS-M) maintains the construct of moral identity as proposed by the original scale with acceptable psychometric properties. This cross-cultural version can be a very useful tool to screen the moral identity of Malaysian youth as baseline data in developing public health-related programs.

\section{ACKNOWLEDGEMENT}

This work was supported by a Universiti Sains Malaysia, Research University Individual (RUI) Grant Scheme with Project No: 1001/PPSP/8012352, Project Code: UO1934 (Reference No: 2020/0202).

\section{REFERENCES}

1. Aquino K, Reed A. The self-importance of moral identity. Journal of Personality and Social Psychology. 2002; 83: 1423-1440.

2. Hardy SA. Identity, reasoning, and emotion: an empirical comparison of three sources of moral motivation. Motivation and Emotion. 2006; 30: $207-$ 215.

3. Blasi A. Moral cognition and moral action: A theoretical perspective. Developmental Review. 1983; 3(2): 178-210.

4. Cheryan S, Bodenhausen GV. When positive stereotypes threaten intellectual performance: The psychological hazards of model minority status. Psychological Science. 2000; 11: 399-402.

5. Tajfel H. Quantitative judgment in social perception. British Journal of Psychology. 1959; 50: 16-29.

6. Erikson EH (1968). Identity: Youth and crisis. New York, NY: Norton; 1994

7. Blasi, A. The development of identity: Some implications for moral functioning. In: G. G. Naom \& T. E. Wren, eds. The moral self. Cambridge, MA: MIT Press; 1993: 99-122

8. Earp BD, Skorburg JA, Everett JAC, Savulescu J. Addiction, Identity, Morality. AJOB Empir Bioeth. 2019; 10(2):136-153.

9. Hardy SA, Bhattacharjee A, Aquino K, Reed A.
Moral identity and psychological distance: The case of adolescent parental socialization. Journal of Adolescence. 2010; 33: 111-123.

10. Sanci L, Webb M, Hocking J (2018). Risk-taking behaviour in adolescents. Aust J Gen Pract. 2018; 47 (12):829-834

11. Brislin RW. Back-Translation for Cross-Cultural Research. Journal of Cross-Cultural Psychology. 1970; 1(3): 185-216.

12. Wang J, Wang X. Structural equation modeling: Applications using Mplus. Chichester, West Sussex, UK: John Wiley \& Sons Ltd; 2012.

13. Hair JF, Black WC, Babin BJ, Anderson RE. Multivariate data analysis. 7th ed. New Jersey, USA: Pearson Prentice Hall; 2013.

14. Kline, R. B. Principles and practice of structural equation modeling. New York, NY: Guilford Publications; 2015.

15. Raykov T, Marcoulides GA. Scale Reliability Evaluation Under Multiple Assumption Violations. Struct Equ Model A Multidiscip J. 2016; 23(2):302_13.

16. Fleiss JL. The Design and Analysis of Clinical Experiments. John Wiley \& Son, Inc: Canada; 1986

17. Al-Sheddi M, Russell S, Hegarty P._How does culture shape our moral identity? Moral foundations in Saudi Arabia and Britain. European Journal of Social Psychology. 2019; 50 (1): 97-110.

18. Department of Statistics Malaysia. Current Population Estimates, Malaysia, 2014-2016. Published 2016. Accessed April 1, 2021. https:// www.dosm.gov.my/v1/index.php?r=column/ cthemeByCat\&cat=155\&bul_id=OWlxdEVoYlJCS 0hUZzJyRUcvZEYxZz09\&menu_id=L0pheU43N WJwRWVSZklWdzQ4TlhUUT09

19. Shafie, F., \& Zainudin, R. Sejarah Malaysia. Penerbit Fajar Bakti Sdn. Bhd: Kuala Lumpur, Malaysia; 2000

20. Azmi MNL, Ching LTP, Jamaludin N, Haziq MN, Habibullah M, Yasser MA, Jayakumar K. The comparison and contrasts between English and Malay languages. English Review. 2016; 4 (2): 209218

21. Hertz SG, Krettenauer T. Does moral identity effectively predict moral behavior? A meta-analysis. Review of General Psychology. 2016: 20(2): 129-140. 
22. Patrick RB, Bodine AJ, Gibbs JC, Basinger KS. What Accounts for Prosocial Behavior? Roles of Moral Identity, Moral Judgment, and Self-Efficacy Beliefs. J Genet Psychol. 2018; 179(5):231-245.

23. Gotowiec $S$, van Mastrigt $S$. Having versus doing: The roles of moral identity internalization and symbolization for prosocial behaviors. J Soc Psychol. 2019;159 (1):75-91.

24. Boegershausen J, Aquino K, Reed A. Moral identity. Current Opinion in Psychology. 2015; 6: 162-166.

25. Alabèrnia-Segura M, Gallardo-Pujol D, Feixas G. Moral Identity Questionnaire (MIQ). Adaptation and Psychometric Properties in Spanish Population. Published 2018. Accessed May 20, 2021. https:// doi.org/10.31234/osf.io/f8kdn

26. Huberts LWJC. Integrity: What it is and Why it is Important. Public Integrity. 2018; 20(4):1-15

27. Coskun K, Kara C. Moral identity test (MIT) for children: reliability and validity. Psicol. Refl.

Crít. 2019; 32 (7): 11-18 